\title{
DESIGN OF CAMERA MOUNT AND ITS APPLICATION FOR MONITORING MACHINING PROCESS
}

\author{
Nadežda Čuboňová', Miroslav Císar ${ }^{1}$ \\ 1 Department of Automation and Production Systems, University of Zilina, SK-010 01 Zilina, Slovak Republic, \\ e-mail: nadezda.cubonova@fstroj.uniza.sk; miroslav.cisar@fstroj.uniza.sk
}

Received: 2015.04.10

Accepted: 2015.05 .08

Published: 2015.06.01

\begin{abstract}
The article deals with the solution to the problem of holding a scanning device - GoPro camera in the vicinity of milling machine EMCO Concept MILL 105, practical part solves the design and production of the fixture. The proposal of the fixture includes the best placing of the fixture within the milling area. On this basis individual variants of this solution are elaborated. The best variant for holding of the camera was selected and fixture production was experimentally performed on a 3D printer - Easy 3D Maker. Fixture functionality was verified on the milling machine.
\end{abstract}

Keywords: camera mount, machine tool, GoPro, turret.

\section{INTRODUCTION}

Continuous development and application of technical and research devices constantly affect our lives, whether it is the area of work, entertainment or education. Implementation of progressive modern technologies to education process is essential for sustaining competitiveness of graduates and educational institutions. Modern technical facilities should aim to promote activity and creativity of students. The article deals with the application of such resources to support teaching which deals with $\mathrm{CNC}$ manufacturing technology. The proposed solution includes the design and production of a mount for GoPro HD HERO 3 camera in the interior of educational machine tool EMCO Concept MILL (CM) 105. The need for such a device from high level of implemented safeguards that prevent machine operates with open door. The device does not enable making recordings of machining process in acceptable quality.

The proposed solution includes design, construction and placement of a special camera mount in machine tool interior. The functionality of the selected solution was tested on a prototype created on a 3D printer - Easy 3D Maker.

\section{DESCRIPTION OF EQUIPMENT}

\section{Camera}

We selected a so-called action camera because of its waterproofness that allows us to use a coolant during machining process without the risk of camera damage and also because of its size, weight, durability and mounting possibilities. Such cameras can usually produce slow motion videos, what is an interesting feature to have for analyzing of the machining process.

The proposed solution uses GoPro HD HERO 3 (Fig. 1). The camera is features video resolutions up to 1080p30, $5 \mathrm{MP}$ photos up to 3 frames per second, an ultra-wide angle lens and built-in Wi-Fi. The camera can be equipped with a wide scale of stands and mounts usually connected together with forks forming angle joints. One of these forks is fitted with M5 closed cap nut and joints are fastened with a knob screw.

\section{Machine Tool}

EMCO CM 105 (Fig. 2) is a compact machine tool designed mainly for education purposes. Tools are stored in ten station turret. Slides and load-bearing elements are made of 


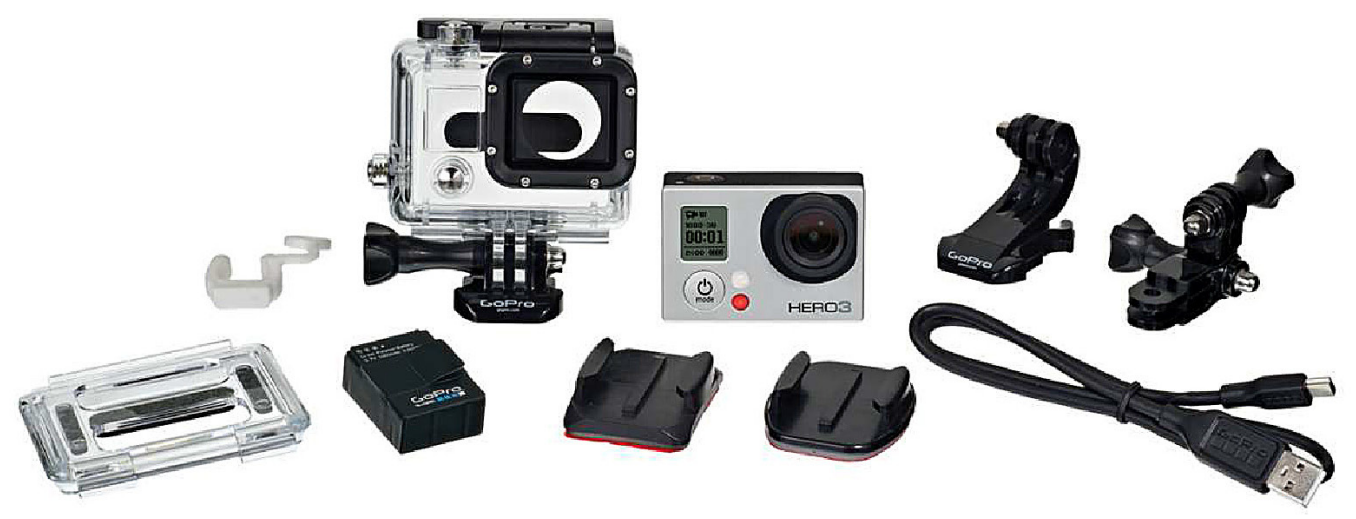

Fig. 1. GoPro HD HERO 3 with standard accessories

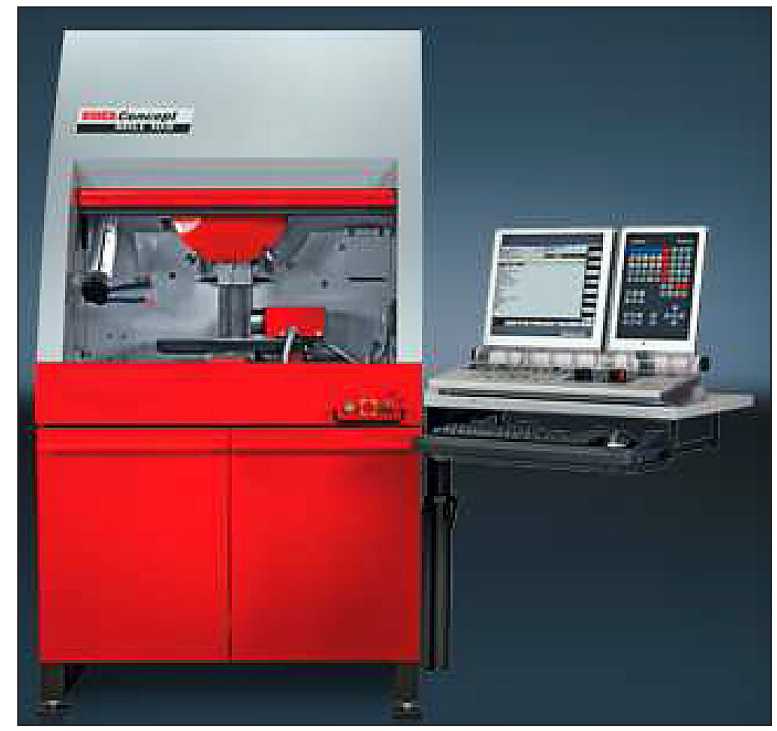

Fig. 2. MCO Concept MILL 105

(www.emco-world.com)

gray cast iron. This machine is equipped with infinitely variable main drive and 10-station turret tool changer. Compact table format is ideal for teaching manufacturing technologies.
Safety glass window provides high level of protection against chips and prevents coolant leakage, but at same time it makes high quality video recording virtually impossible because of reflections. The control for the CM 105 is connected via PC with interchangeable WinNC control from EMCO.

Workspace (Fig. 3) provides a capability of clamping workpiece with dimensions $200 \times 150 \mathrm{~mm}$ and its maximum size in $Z$ axis depends on the length of used tool. Effective length of $Z$ axis is $150 \mathrm{~mm}$. Inner space of machine tool is significantly larger than effective workspace, therefore there is more than enough space for a placement of small action camera mentioned above.

\section{DESIGN OF CAMERA MOUNT}

Combination of specific selected camera and machine tool provides several possible places for mounting (Fig. 4), each of which provides different type of view:

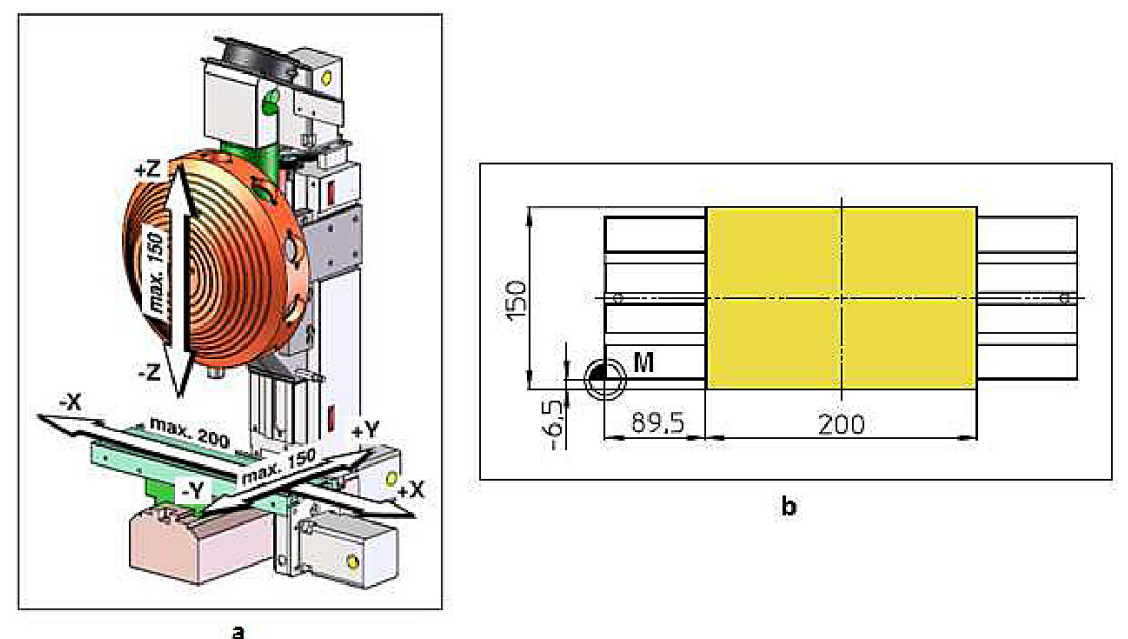

Fig. 3. Size of EMCO CM 105 workspace 


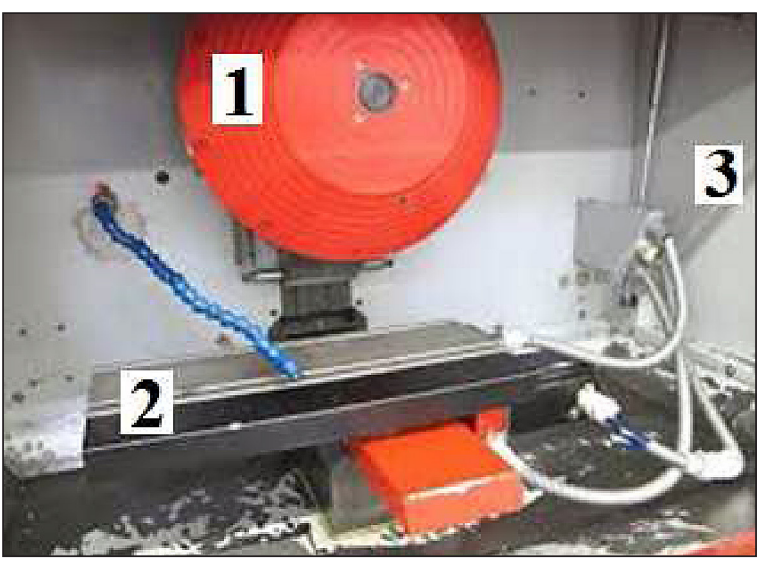

Fig. 4. Spots for camera placement at workspace of EMCO CM 105

1) mounting on turret - tool POV,

2) mounting on worktable - workpiece POV,

3) mounting on machine tool frame - static video.

This proposal deals only with mounting on turret, which provides a tool point of view what eliminates possible problems with changing focusing distance. Turret have ten positions, therefore, the mount had to allow recording individual tools in their specific positions. The camera and mount components should not affect production capability of the machine tool in any negative way and operation of machine should not affect the camera and its stability. There were two basic designs of mounting on turret. First one (Fig. 5 - left) uses several mounting places - one for each tool and camera have to be remounted after each tool exchange - usually several times during machining one part. This design uses standard GoPro mounts glued on turret. A problem with this design is that flat part of turret is too small to place ten of them, therefore, we had to use only five mounts placed equidistantly around the turret.

Second design (Fig. 5 - right) uses a pendulum-like construction mounted in the center of the turret. This design removes necessity for manual manipulation with camera during each tool exchange. As turret spins during tool exchange, the camera keeps facing downwards because it is oriented by gravity. This way, the camera is constantly facing the tool which is currently active. Below is a further elaboration of this design.

The comparison of these two variants resulted to further development and implement the second mentioned variant. The decisive advantage was lack of necessity for manual handling of camera during machine tool operation.

\section{DESIGN OF PENDULUM-LIKE VARIANT}

Principle of pendulum requires at least parts which move relatively to each other. One part has to be fixed on a turret as close to its center of rotation as possible, in order to reduce unwanted movement of the camera during tool exchange.

First, we planned to use only the parts printed on 3D printer (Fig. 6 - left). The biggest disadvantage of this design is relatively high friction between moving components, which can affect fluency of movement and cause vibration during tool exchange, but on the other hand, it is easy to produce.
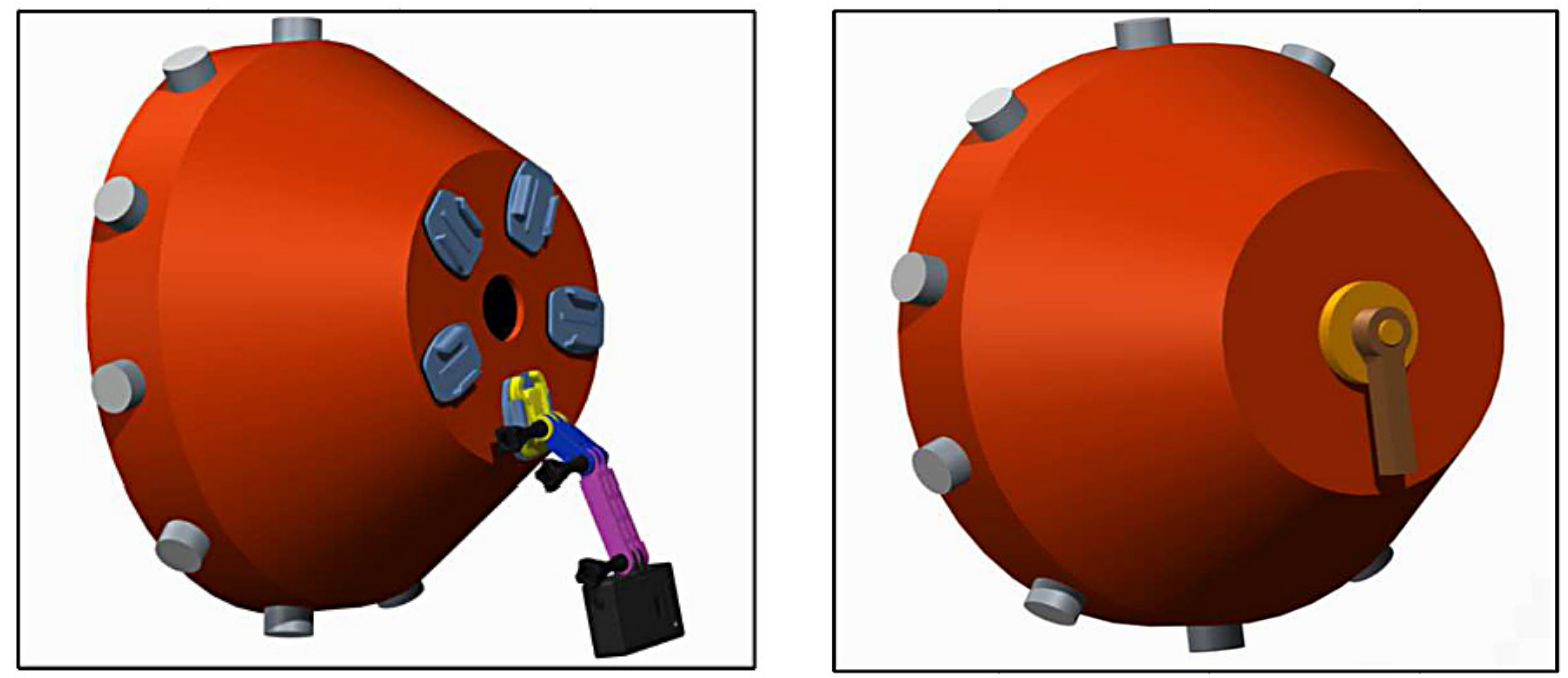

Fig. 5. Variants of camera mounting on turret 

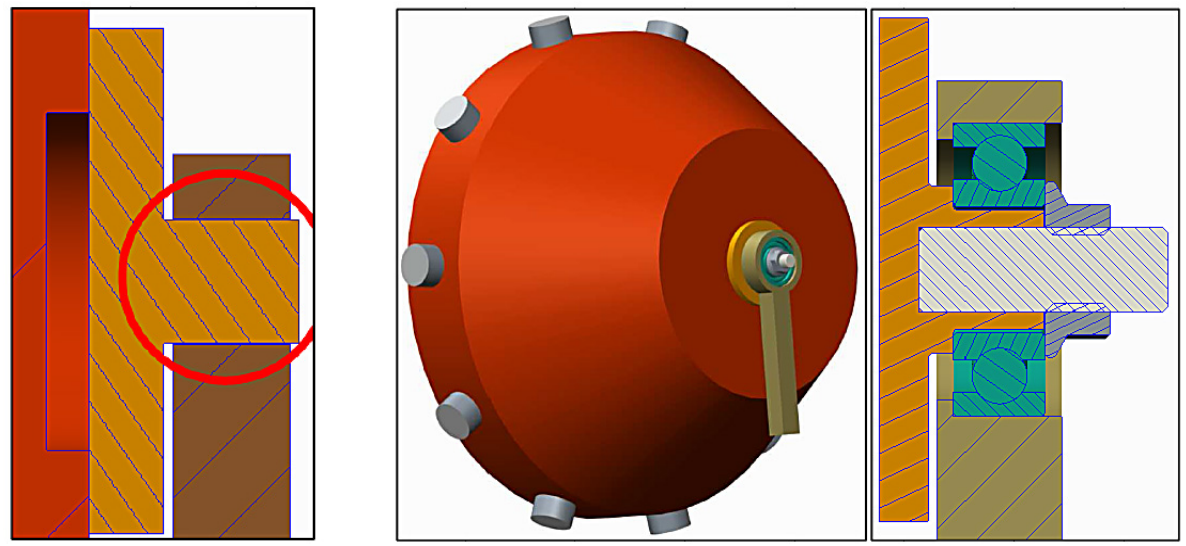

Fig. 6. Variants of pendulum construction

An improved variant (Fig. 6 - right) includes a ball bearing and other standardized parts in order to make movement more fluent and prevent jams and vibrations. We decided to make the mount demountable, therefore, the pivot was designed with loose fit. The bearing is fixed and aligned in place with a nut and rod with thread on the end glued in the center of pivot. Placing the camera and assembling the whole mount can be done without tools, just by bare hand.

Another task was to allow positioning the camera in space. This can be done either by using standard camera accessories or by modifying current design of our mount. We decided to use several simple parts to form a mount compatible with standard camera accessories. The designed construction allows simple positioning of camera in workspace in order to precisely aim the camera to an active tool at the angle suitable for recording.

The final construction (Fig. 7) consists of rotary joint described above, angle joint connect- ing rotary section with carrier rod with attached clamp with standard fork that allows connection of camera or its equipment.

Carrier rod is made of long Allen screw, screwed into a nut glued in hexagonal hole in one part of the angle joint. Using standard size thread allows us to easily replace carrier rod by another screw with different length if necessary. Screw head serve as stopper that prevents a slip-off and fall of the camera.

Clamp (Fig. 8) consists of two plastic parts printed on 3D printer and fastened with two standard M5 nuts glued in hexagonal holes and two wing screws. Camera case can be connected to clamp via simplified version of fork that together with its counterpart forms angle joint. We expect just small vibrations, negligible forces and acceleration and generally small forces. Therefor we were able to use simplified fork with just two tines. Such a solution provides less friction and higher stiffness of the fastened joint but it is suffi-
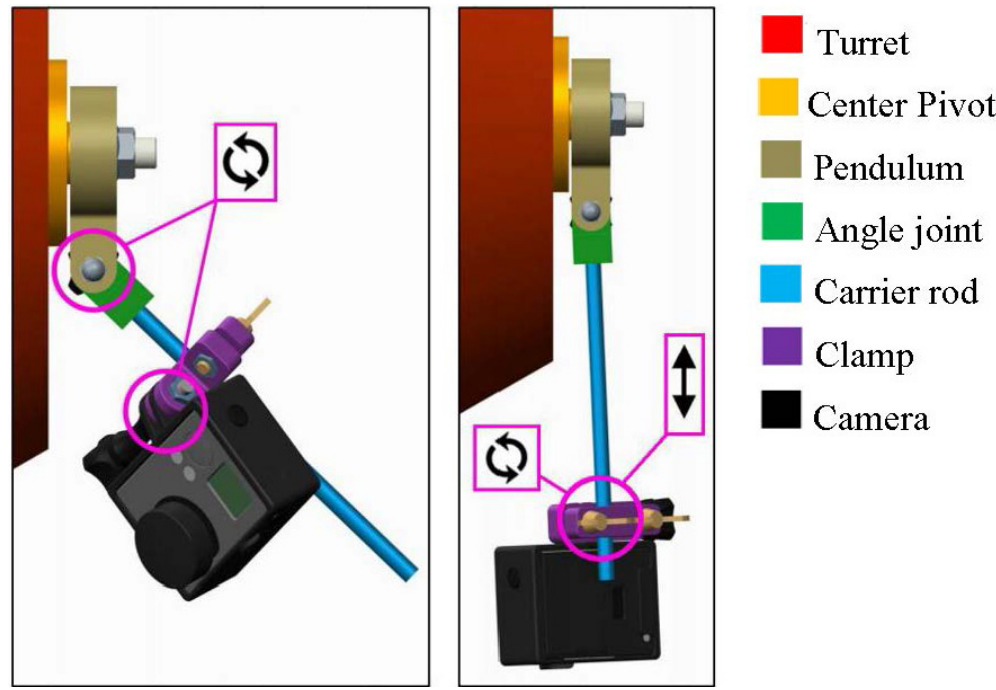

Fig. 7. Final design of camera mount on turret 


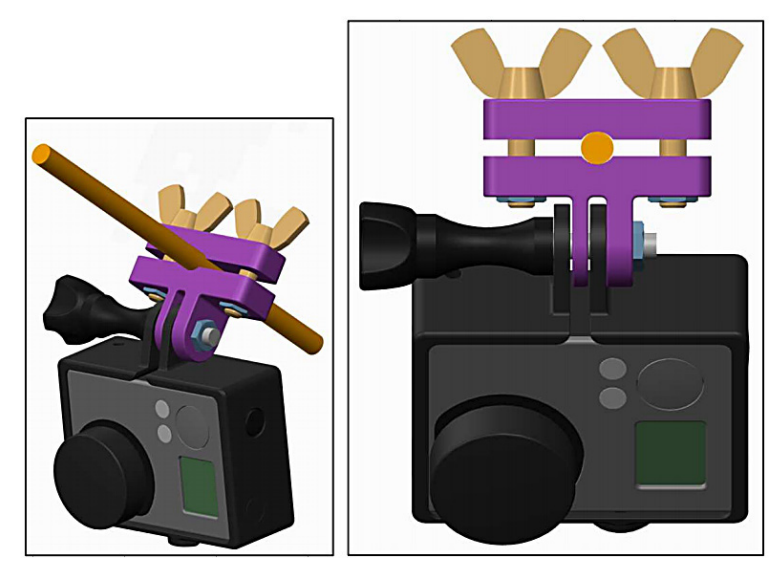

Fig. 8. Mounting camera on carrier rod

cient for the described application and at the same time, it is less demanding on accuracy of parts printed on a $3 \mathrm{D}$ printer.

\section{DESIGN VERIFICATION}

All parts were designed in Autodesk Inventor 2013. Models were printed on 3D printer Easy 3D Maker from PLA material. Industrial double sided tape was used for mounting central part to turret. Epoxy was used to fix nuts into hexagonal holes and bearing into pendulum.

Field of view provided by used camera (GoPro HERO 3 Silver edition) is wide more than enough for purposes of capture of machining process.

\section{FURTHER IMPROVEMENTS}

The fact that mount places camera too close to the active tool to focus on it properly was discovered after a short period of usage. Such a problem can be solved in several ways. We decided to use so called close up filter. There are several commercial solutions for used camera, but we used material that was virtually laying around $-58 \mathrm{~mm}$ close up filter $\times 2$ and step up ring 37 to $58 \mathrm{~mm}$. A rectangle of the same size as the front part of the camera case was milled into the stepped ring, which was glued on a 3D printed adaptor designed to fit on front element of the camera lens. The inner surface of 3D printed part was covered by rubber tape in order to increase friction between camera case and filter mount.

Such a big diameter of close up filter was selected in order to reduce the risk of picture vignetting. Figure 10 shows parts of described accessory and its mounting on camera case. A test confirmed that, with a close-up filter attached, the camera is able to focus on tool properly and quality of recorded video increased dramatically.

A disadvantage of this solution is that it reduces possibility of usage camera and described mount in machine working with coolant because of non-waterproofness of the ring adaptor.

The laboratory where the described machine tool is placed is equipped with an interactive whiteboard. Therefore, we decided to use
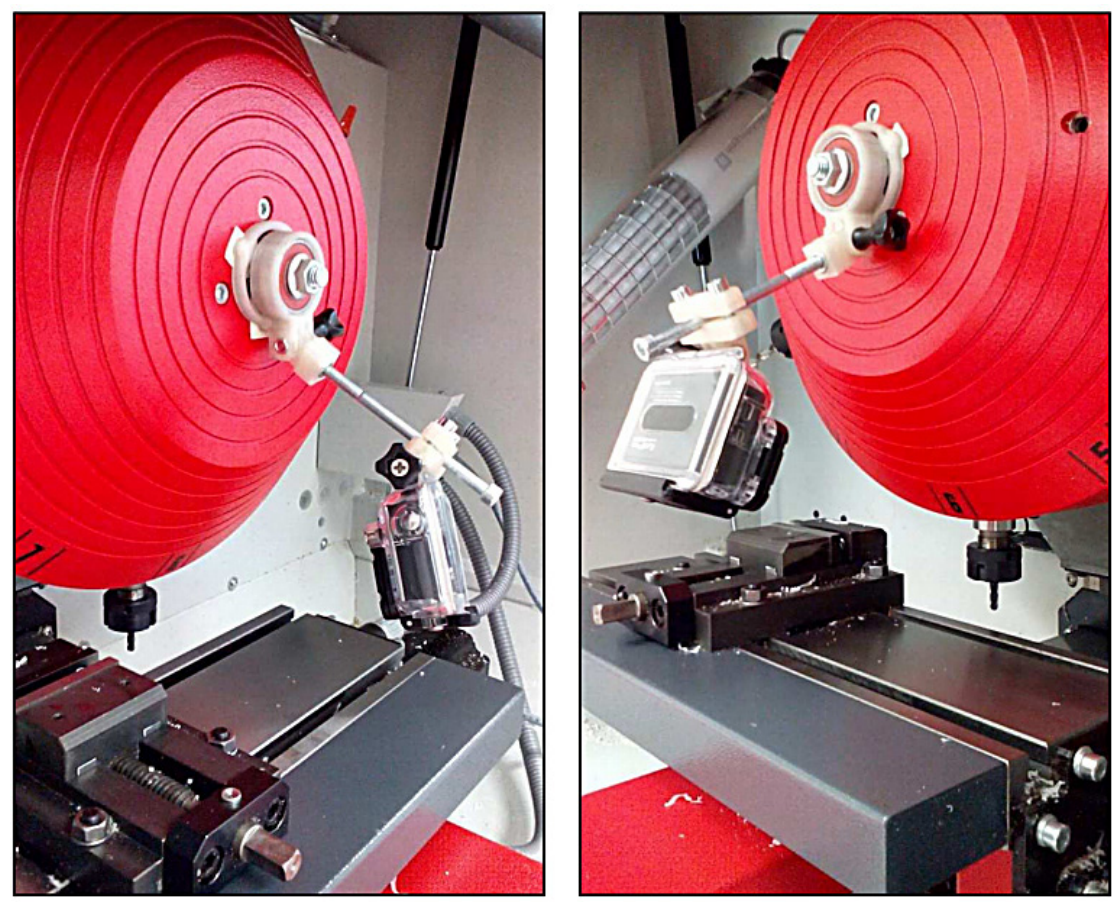

Fig. 9. Camera mounted in machine tool 

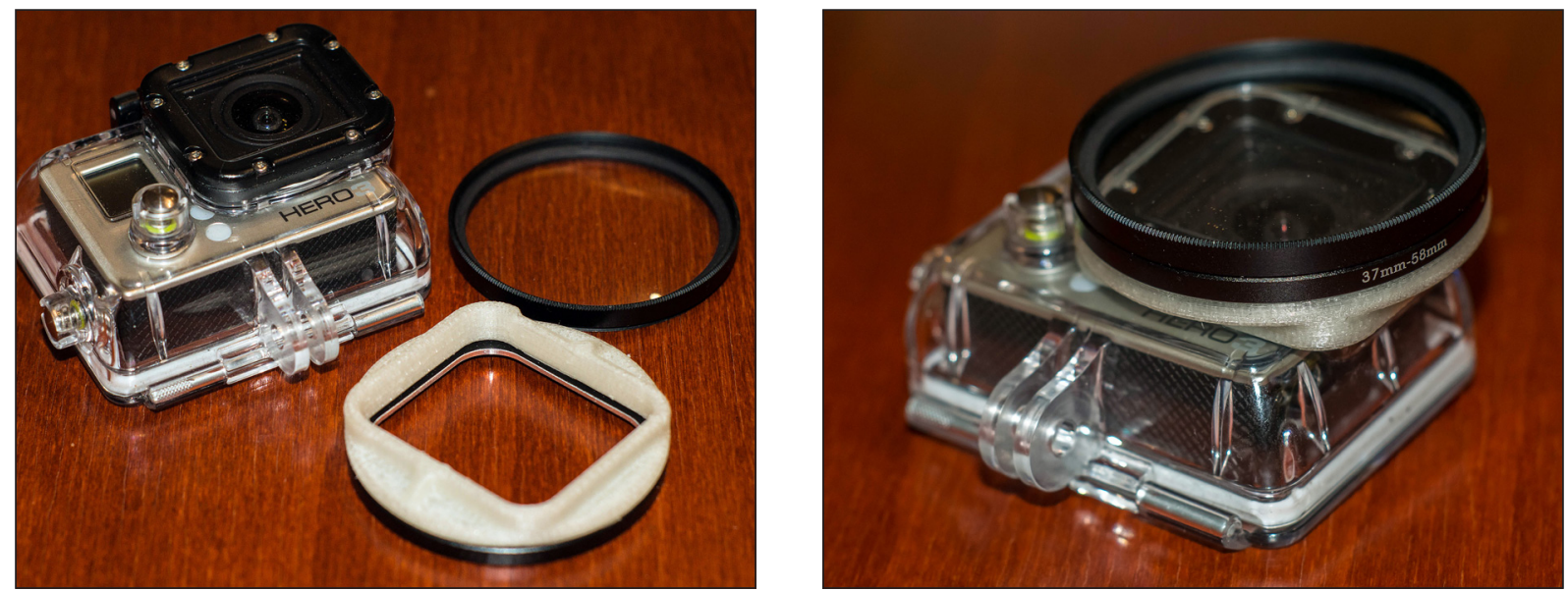

Fig. 10. Close up filter and its mounting

the function of streaming video from the camera through a wireless network. Wi-Fi dongle was attached to a computer in order to connect it to the camera. We used VLC player to open video stream from camera on the computer. Normally, such a function can be used just with mobile device, but address of video stream is stored in camera and it can be obtained with web browser from camera IP address on port 8080 (usually http://10.5.5.9:8080/ ). This webpage contains a tree structure, folder "live" should contain file "amba.m3u8" URL address of this file is the address for network stream that can be opened as a network stream in VLC player.

In this way the device can be used not only for recording video of machining but also for supervising of long processes or as teaching aid. Usually it is impossible to observe machining process for more than a few people simultaneously, but with this device we are able to show almost real time image from machine tool in an interactive whiteboard or even in multiple screens.

The above-mentioned machine tool is usually used for machining aluminum. There is a small, but not negligible risk of damaging surface of camera, case, lens or close up filter by flying sharp and hot chips produced in machining. In order to reduce possible damage we first used $58 \mathrm{~mm}$ clear glass filter but it was too thick and it caused vignetting. Better results were obtained by covering the close-up filter with clear kitchen foil. It is soft and it can be easily damaged but it protects front element well enough; it is cheap and easy to replace. There is almost none visible decrease of video quality caused by foil application if it is straightened properly and all bubbles are removed.
Even with the front element protected it is better to set the camera position high where it is not in a path of flying chips, in order to reduce a risk of video quality reduction during machining process and necessity for replacement of protecting filter. It is relatively easy to find a damaged spot on the foil and therefore it can be used to verify the position where is safe to place the camera without protection.

\section{CONCLUSION}

Implementation of multimedia devices, such as cameras, become an essential part of modern teaching practices, therefore, it is important to utilize available technology and to develop new ways to use it to further improve.

The proposed solution of mounting a camera in a machine tool workspace allows to freely set up the height and angle of the camera. Moreover, height setup is not limited to standard heights, as it would be with standard accessories, construction with a carrier rod and clamp allows to set up the position to any necessary height.

There are several possible variations of camera placement in machine tool workspace, such as mounting on a worktable, machine tool frame, etc. This article deals with just one of them. Design of other mounting systems can be solved as a part of future development.

\section{Acknowledgements}

This article was made under support projects KEGA 037ŽU-4/2014 "The Development of Complex Interactive Educational Portal for Support the Teaching of CNC Production Machines Programming". 


\section{REFERENCES}

1. Náprstková N., Hricová J.: Př́ípravky a nástroje: programování výrobných strojů. Ústi nad Labem: Fakulta Výrobných Technológií a Manažmentu, 2012, pp. 206.

2. Machine Description EMCO CM 105, EMCO Maier Ges.M.b.H.,EditionA2003-02,70s.Red.No.EN2105 EMCO GROUP. 2013. Concept Mill 105. [online]. Online: <http://www.emco-world.com/en/products/ industrialtraining $/$ machines $/$ milling $/ \mathrm{cat} / 26 / \mathrm{d} / 2 / \mathrm{p}$ /1000045\%2C26/pr/concept-mill-105/view/11.html>
3. Didactic Martin, s. r. o. 2007. Technický popis Concept MILL 105: Stolné CNC obrábacie centrum pre frézovanie vítanie a rezanie závitov $\mathrm{s}$ vymenitel'ným riadiacim systémom. 2013, Online: <http://www.didactic.sk/Data/802/UserFiles/ emco_tech_popisy/spec_cm105-sk.pdf>

4. GoPro, Inc. 2013. GoPro HERO 3 Silver edition. 2013, Online: <http://gopro.com/cameras/hd-hero3-silver-edition\#technical-specs>

5. Martinka L.: Proposal and production of sensing device clamping (in Slovak). MSc. thesis, University of Zilina, 2014. 